\title{
Older adult loneliness: myths and realities
}

\author{
Pearl A. Dykstra
}

Published online: 4 April 2009

(c) The Author(s) 2009. This article is published with open access at Springerlink.com

\begin{abstract}
The focus in this paper is on the social domain of quality of life, and more particularly loneliness. The empirical literature on older adult loneliness is reviewed, thereby challenging three often-held assumptions that figure prominently in public debates on loneliness. The first assumption that loneliness is a problem specifically for older people finds only partial support. Loneliness is common only among the very old. The second assumption is that people in individualistic societies are most lonely. Contrary to this belief, findings show that older adults in northern European countries tend to be less lonely than those in the more familialistic southern European countries. The scarce data on Central and Eastern Europe suggest a high prevalence of older adult loneliness in those countries. The third assumption that loneliness has increased over the past decades finds no support. Loneliness levels have decreased, albeit slightly. The review notes the persistence of ageist attitudes, and underscores the importance of considering people's frame of reference and normative orientation in analyses of loneliness.
\end{abstract}

Keywords Loneliness - Quality of life · Cross-national comparison · Ageing $\cdot$ Change over time

\section{Introduction}

Quality of life is a complex, multifaceted construct that requires multiple approaches from different theoretical

P. A. Dykstra $(\bowtie)$

Netherlands Interdisciplinary Demographic Institute (NIDI), PO Box 11650, 2502 AR The Hague, The Netherlands e-mail: dykstra@nidi.nl angles (Diener and Suh 1997; Walker and Mollenkopf 2007). It is based both on objective circumstances and subjective evaluations (Motel-Klingebiel et al. 2004), but the two tend to be only modestly correlated (Diener and Suh 1997). The latter finding underscores the importance of considering people's expectations and reference levels both within and across nations (Delhey 2004; Walker 2005). The concept of quality of life has micro and macro components (Motel-Klingebiel et al. 2004). It can be regarded as the outcome of advantages and disadvantages experienced over the course of life, which in turn are shaped by the larger social, cultural, legal, economic, and historical context. Given the complexity of the concept and the existence of different disciplinary perspectives, it should not come as a surprise that there is little consensus about how to conceptualize and measure quality of life, and no comprehensive theoretical model (Halvorsrud and Kalfoss 2007; Walker 2005). Measures have typically included a series of life domains: physical, emotional, social, environmental, and material (e.g. Andrews and Withey 1976; Skevington et al. 2004).

The focus in this paper is on the social domain of quality of life-usually measured by indicators of social networks, support, participation in activities and community integration (Bowling 2004 as cited in Walker 2005 and in Walker and Mollenkopf 2007). More specifically, I focus on loneliness, which is the unpleasant experience that occurs when a person's network of relationships is felt to be deficient in some important way (De Jong Gierveld 1987; Peplau and Perlman 1982). An often-used definition of loneliness is that it involves an unwanted discrepancy between the relationships one has and the ones one would like to have (Perlman and Peplau 1981). One hallmark of loneliness is that it is a subjective experience. A second is that it involves negative affect. Loneliness is more strongly 
associated with qualitative than with quantitative characteristics of relationships (Hughes et al. 2004; De Jong Gierveld 1998). It is important to draw the distinction between loneliness and social isolation (De Jong Gierveld et al. 2006). Loneliness is a negative, subjective experience, whereas social isolation is the objective condition of not having ties with others.

Following Weiss (1973), it has become common to distinguish emotional and social loneliness (Drennan et al. 2008; Dykstra and Fokkema 2007; Perlman 2004; Van Baarsen et al. 2001). Emotional loneliness is missing an intimate attachment, such as a marital partner, and is accompanied by feelings of desolation and insecurity, and of not having someone to turn to. Social loneliness is lacking a wider circle of friends and acquaintances that can provide a sense of belonging, of companionship and of being a member of a community.

Explanations of loneliness are generally sought in three sets of factors (see De Jong Gierveld 1998; De Jong Gierveld et al. 2006; Pinquart and Sörensen 2001; Wenger et al. 1996). The first pertains to social network characteristics: the number and the quality of the relationships in which people are involved. Research has repeatedly shown that the unmarried are lonelier than the married, and that those with small, unsupportive networks are lonelier than those who are actively involved in social networks. The second set of determinants pertains to relationship standards: the preferences, expectations and desires for personal relationships. Loneliness arises when the relationships people have do not meet their standards. A focus on relationship standards can help understand why people who are socially isolated do not feel lonely, or why people who are embedded in large networks nevertheless feel lonely (Dykstra and Fokkema 2007; Dykstra 1995). The third set pertains to predisposing conditions: factors that might explain why people have deficiencies in their social networks. Poor self-esteem is one of them: people who lack confidence might be inhibited in their social interactions, and might not be attractive to others. Poor social skills are another predisposing condition, as is poor health.

This paper provides a review of the literature on older adult loneliness. In this review, I will challenge three often-held assumptions that figure prominently in public debates on loneliness. The first is that loneliness is a problem specifically for older people. The second is that people in individualistic societies are most lonely. The third is that loneliness has increased over the past decades. I will deal with the three assumptions successively, and review the empirical evidence to find out to what extent they are supported by research findings. The research pertains to studies conducted in Europe and North America.
Is loneliness a problem specifically for old people?

The image of the elderly in the general public is that of an overwhelmingly lonely group (Revenson 1986; Tornstam 2007; Victor et al. 2002). In surveys carried out among the general public, loneliness is often named as a very serious problem for older adults (National Council on the Aging 2000; Tornstam 2007; Victor et al. 2002). In a recent US study (Abramson and Silverstein 2006), respondents greatly overestimated the prevalence of loneliness in the older adult population. The extent of loneliness among older people was overestimated in scope by the elderly themselves, although generally not to the degree of overestimation among Americans under the age of 65. Sixtyone percent of 18-34-year olds, $47 \%$ of 35-64-year olds, and $33 \%$ of those aged 65 and above perceived loneliness as a serious problem "for most people over 65 ". Thirteen percent of those aged 65 and over gave an affirmative answer to the question of whether loneliness was "a serious problem ... for [them] personally". In other words, people tend to attribute higher levels of loneliness to the elderly than the elderly themselves experience.

Becoming old is often equated with becoming lonely. How much evidence is there for this belief? Figure 1 provides a summary of findings on age differences in loneliness (based on overviews of cross-sectional studies in De Jong Gierveld 1998; Perlman and Peplau 1984; Pinquart and Sörensen 2001). The figure shows the lowest, highest and median proportion of respondents in five age groups reporting feeling lonely "often" across approximately 40 surveys. The results suggest that loneliness is common only among the very old. Between 20 and 30\% (depending on the cross-sectional survey) of middle-aged and young-old respondents report moderate or serious loneliness. However, at advanced ages, the prevalence of loneliness increases. Of those aged 80 and over, $40-50 \%$

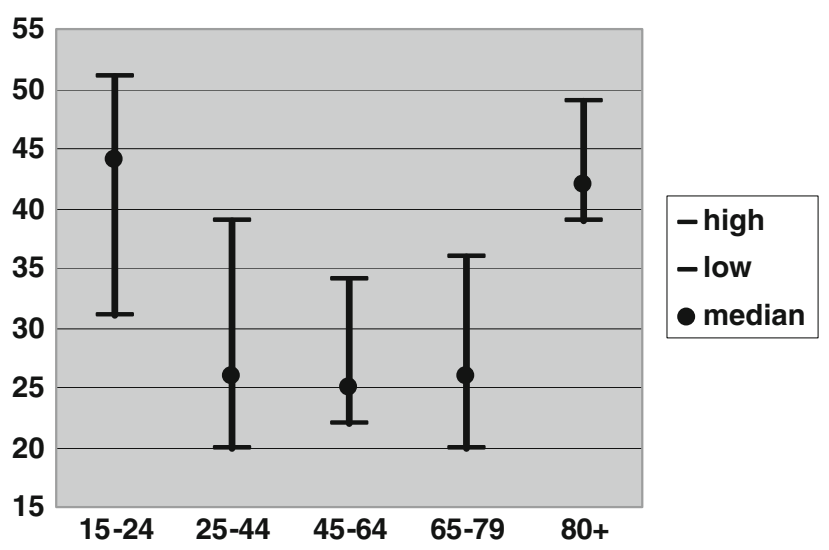

Fig. 1 Reports of loneliness, by age (\%). Based on findings reported in De Jong Gierveld (1998), Perlman and Peplau (1984), Pinquart and Sörensen (2001) 
say they are "often" lonely. Interestingly, the prevalence of loneliness is also high among the youngest respondents, those between the ages of 15 and 24 .

Longitudinal data on changes in older adult loneliness show a similar pattern: increases in loneliness only among the very old. In a nationally representative study conducted in the Netherlands over a 7-year period (Dykstra et al. 2005), loneliness increased slightly among the young old (age 55-75 at time 1), but it increased quite dramatically at advanced ages $(75+$ at time 1$)$. Danish data $(N=4,600)$ covering a 5-year period show an over-representation of the eldest $(70+)$ at the two points of measurement (Platz 2005). In a population-based prospective longitudinal study carried out in Tampere, Finland (Jylhä 2004), those who recovered from loneliness over a 10 -year period tended to be younger $(M=65.9$ years at time 1$)$, while those who reported not being lonely at time 1 but reported loneliness at time 2 tended to be older ( $M=67.5$ at time 1$)$. Findings from the Zutphen Elderly study in the Netherlands in which men born between 1900 and 1920 were followed over time (Tijhuis et al. 1999) show an increase in loneliness over a 10-year period only for the very old (aged 75-85 at time 1). Findings contrary to the general pattern of an increase in loneliness among the very old are reported by Samuelsson et al. (1998). In this longitudinal Swedish study virtually no shifts in loneliness were observed in a sample of rural older adults (67-80 years of age at time 1) who were followed over a 13-year period. Note, however, that the Swedish sample was rather small $(N=143$ at time 1$)$. Representative studies on ageing and older adult loneliness in other countries have not been carried out.

\section{Are people in individualistic societies most lonely?}

Reher's (1998) seminal paper on family ties in Western Europe has served as a framework for many comparative studies. Reher characterized the center and north of Europe by weak family links, and the Mediterranean by strong family ties. In countries with weak family ties, young adults set up households of their own at a relatively young age, and provision of care to vulnerable family members is largely accomplished through public and private institutions. In countries with strong family ties, young adults remain in the parental home until they marry, and much of the aid given to the needy and the poor comes from the family. In weak family areas, individualistic values tend to dominate, whereas collectivistic values predominate in strong family contexts.

Family solidarity patterns in Western Europe are generally described in terms of a gradient running from a more individualistic tradition in the north to a more collectivistic tradition in the south. In their ranking of countries on the basis of family obligation norms, Kalmijn and Saraceno (2008) report a "North-South element" (p. 492) but also point to the relatively familialistic position of Germany and Austria. Hank (2007) shows that the prevalence of coresidence of older parents with their children is lowest in the Scandinavian countries and the Netherlands, highest in the Mediterranean countries, while intermediate levels are reported for the central region of Europe. The frequency of parent-child contacts exhibits "a similar north-south pattern" (p. 162). In their comparison of older adults' living arrangements in six European countries, Tomassini et al. (2004) show that the proportion of people aged 85 and over residing in institutions is lowest in Portugal and Italy followed by Austria, has an intermediate level in Great Britain, and is highest in the Netherlands and Sweden. They also show that the proportion of women aged 65 and over living alone in private households is considerably lower in southern European countries than in central and northern European countries.

Given the higher levels of institutionalization and solitary living in countries with an individualistic tradition, it seems reasonable to suppose that levels of older adult loneliness are also higher there. Is this pattern observed in cross-national comparative data? Findings from studies on country differences in loneliness are summarized in Table 1. They are based on single-item direct measures of loneliness, whereby respondents are asked "Do you feel lonely" using the answer categories "often", "sometimes", or "never".

Walker's (1993) publication is based on the 1992 Eurobarometer (number 37.2) which was a special survey of the population aged 60 and over in twelve member states (this is the most recent Eurobarometer survey enquiring into older adult loneliness). Between 5 and $20 \%$ of older Europeans say they often feel lonely. Wide variations between countries can be observed, however. The southern European countries show a high prevalence of loneliness, while loneliness among older adults is less common in western and northern Europe.

An earlier study using data from six European regions (urban centers or major cities) participating in the World Health Organization Eleven Country Study on Health Care of the Elderly (Jylhä and Jokela 1990) revealed roughly the same pattern. Respondents were between the ages of 60

Table 1 Older adults who often feel lonely, by country (\%)

\begin{tabular}{ll}
\hline Denmark & $<5$ \\
Finland, Germany, Netherlands, UK & $5-9$ \\
Belgium, France, Ireland, Luxembourg, Spain & $10-14$ \\
Italy, former Yugoslavia & $15-19$ \\
Greece, Portugal & $>19$ \\
\hline
\end{tabular}

Based on findings reported in Jylhä and Jokela (1990), Walker (1993) 
and 90. The results show, for both older adults living alone and those living with one or more others (e.g. a partner, children, other family members), that the prevalence of loneliness was the lowest in Germany and Finland, higher in Italy and former Yugoslavia, and very high in Greece.

A study by Heikkinen et al. (1995) showed no significant differences between three urban localities in Sweden, Finland and Denmark in the prevalence of loneliness among 75-year olds. These authors assessed the frequency of occurrence of loneliness during the previous week on the basis of the loneliness item in the Center for Epidemiologic Studies Depression Scale (CES-D, Radloff 1977). In each of the localities, women were more likely than men to report loneliness. The lowest prevalence of loneliness was recorded for Swedish men (5\%) and the highest for Danish women $(27 \%)$.

De Jong Gierveld and Van Tilburg (1999) examined differences in loneliness between older adults in the Netherlands and Tuscany, Italy. At the time of the survey the Dutch respondents were between the ages of 55 and 90 , whereas the Tuscan respondents were between the ages of 56 and 91. Dutch and Italian older adults had similar mean scores for the item "I sometimes feel lonely, with answer categories "no" (1), "more or less" (2), and "yes" ( $M=1.50$ and 1.47 , respectively). These findings are contrary to Walker's (1993) report of higher levels of loneliness among Italian than Dutch older adults. Note, however, that when the De Jong Gierveld loneliness scale was used (De Jong Gierveld and Kamphuis 1985), which consists of 11 items assessing the presence and quality of the social network, the Italians showed higher levels of loneliness than the Dutch (see also Van Tilburg et al. 1998).

Data on the prevalence of loneliness in former communist countries are rare. De Jong Gierveld's (2008) study is unique in that it involves a comparison between France, Germany, the Russian Federation, Bulgaria and Georgia. Her data on 60-79-year olds are from the Generations and Gender Surveys (United Nations 2005) which uses a short version of the De Jong Gierveld loneliness measure (De Jong Gierveld and Van Tilburg 2006) with scores ranging from 0 , not lonely, to 6 , severely lonely. Mean loneliness levels are highest in the former communist countries. The means are 1.5, 1.5, 2.5, 3.1 and 3.8 for France, Germany, the Russian Federation, Bulgaria and Georgia, respectively.

In summary, the overall pattern in Western Europe appears to be that of a North-South divide, but one that is contrary to the general belief that older adults in individualistic countries are most lonely. Older adults in northern European countries, which are viewed as being most individualistic (Reher 1998) tend to be less lonely than older adults in southern European countries, which are viewed as being more strongly family-oriented. The scarce data on central and eastern European countries suggest a high prevalence of loneliness among older adults.

\section{Explanations of cross-national differences}

If cross-national differences are observed, the question arises as to how to explain them. What factors account for differences across countries? Three types of explanations can be put forward (see Fig. 2). The first is that the inhabitants of the different countries have different individual characteristics, and thus that the differences might be attributable to differences in population composition. The second explanation is that the countries as a whole are different. In this kind of an explanation references might be made to differences in cultural systems, economic organization, policy arrangements, and so forth. The third explanation is that there is an interaction between individual and country characteristics, implying that the importance of a particular individual-level predictor might vary between countries. One should note that these explanations are not mutually exclusive. In what follows, I describe, for purposes of illustration, examples of empirical studies in which the different kinds of explanations of cross-national differences have been applied.

\section{Population composition}

A common procedure is to examine whether the distribution of determinants differs across countries, and subsequently whether this distribution accounts for crossnational differences. Van Tilburg et al. (1998) studied differences in loneliness among older adults in Tuscany, Italy, and the Netherlands. Mean loneliness scores were higher in Italy than in the Netherlands. Fourteen indicators of social integration were included in the analyses (e.g. living alone, network size, church attendance, support received). Results showed that the Tuscans were less likely than the Dutch to be living alone, more likely to be living with children, less active in voluntary associations, and less likely to be involved in volunteer work. In addition, the Tuscans had smaller networks, but received more social and emotional support per network member. The main finding was that the higher level of loneliness among the

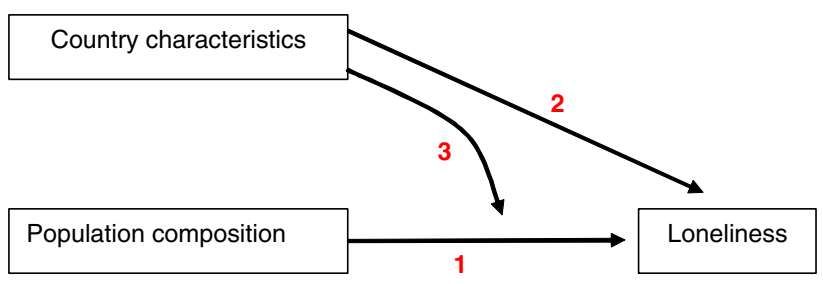

Fig. 2 Explanations of cross-national differences in loneliness 
Tuscans was attributable to being less socially integrated than the Dutch. On the average, Tuscan older adults had fewer friends, less intensive contacts with their neighbours, and fewer exchanges with family members, and that was why they were more vulnerable to loneliness than their Dutch counterparts.

\section{Country characteristics}

Here I draw on a study of general life satisfaction, given the absence of relevant studies on loneliness. Pooling harmonized Eurobarometer data from 28 countries in Europe, Delhey (2004) studied opportunity for need fulfilment as a determinant of life satisfaction, both at the individual and country level. In the survey people were asked whether they were "very satisfied", "fairly satisfied", "not very satisfied" or "not at all satisfied" with their life in general. His selection of country-level predictors was guided by a modernization theoretical framework which posits that technological progress not only leads to improved material living conditions, but also reflects a growing demand for participation in political decisionmaking and a demand for greater equality. Significant predictors at the country-level were: income per capita in purchasing power, the share of the labour force working in the tertiary sector, political freedom, population size, and income inequality. All predictors with the exception of population size showed positive correlations with life satisfaction. In terms of individual-level characteristics, next to rich-poor status, being young, being healthy, having a job and having a partner are the factors driving life satisfaction. Country characteristics were significantly associated with life satisfaction over and above personal characteristics.

\section{Interaction effects}

Jylhä and Jokela (1990) formulated the hypothesis that older adults who live alone are more likely to feel lonely in countries where living alone is uncommon. In other words, loneliness should be more prevalent in societies where living alone is more of an exception than a rule. The authors based this hypothesis on Johnson and Mullins' (1987) concept of the "loneliness threshold". This concept holds that people have their own minimal standards for social contacts, determined by two closely related factors: the cultural value system in a society and the amount of social contacts to which people are normally accustomed. In more collectivist cultures, pressures and expectations of communality are likely to be higher than in a more individualist type of culture. Living alone is more typical of individualistic than of collectivist societies. In line with their hypothesis, Jylhä and Jokela found that levels of loneliness among those living alone were higher in places where solitary living was rarest. A multivariate analysis of the data of older adults in Finland and Greece, two countries which are not only geographically but also culturally distant, revealed that the cross-national differences continued to exist when differences in health and the proportion living alone were taken into account. Presumably, Finnish older adults have fewer expectations about community and frequent and close interaction with friends and family than do Greek older adults. The reason Finnish older adults who live alone are less prone to loneliness than their Greek counterparts is that they are less likely to meet disappointments in their relationships. In the more individualistic societies of the North, older adults seem more content living alone and might view co-residence with children as a defeat.

Among the studies focusing on cross-national differences in loneliness, explanations in terms of interaction effects are most often practiced, probably because the number of countries with comparative loneliness data tends to be small. In an Anglo-Dutch comparison, for example, Scharf and De Jong Gierveld (2008) demonstrated that neighborhood characteristics were more important in explaining variations in loneliness scores among older adults in England than in the Netherlands, a finding that is consistent with differences in public policy regimes between the two countries. Though England and the Netherlands are broadly similar in terms of their socioeconomic development, the Netherlands has a stronger tradition of housing policies aimed at reducing social and economic inequalities. Van Tilburg et al. (2004) examined differences in older adult loneliness between the Netherlands, Tuscany, Italy, and Manitoba, Canada. The predictors of loneliness were highly similar across the three countries, with one exception: in the Netherlands living with a partner provided greater protection against loneliness than in Tuscany or Manitoba. The authors, however, do not provide an interpretation for this finding.

\section{Has loneliness increased over the past decades?}

In the popular press it is often suggested that loneliness has increased over the past decades. Underlying reasons are: the increasing proportions of people living alone, increasing divorce rates, the declining size of kinship networks as the result of the drop in birth rates, the disruptive effects on personal relationships of increasing social and geographic mobility, and so forth. But how much evidence is there for increasing levels of loneliness over time?

Van Tilburg (2005) acquired data from over 30 studies on loneliness conducted in the Netherlands over a 20-year period. Each of these studies used the 11-item De Jong Gierveld loneliness scale to measure loneliness (De Jong 
Gierveld and Kamphuis 1985). Van Tilburg restricted his analyses to non-institutionalized respondents ranging in age from 18 to 90 . He also controlled for whether the data were collected in a face-to-face interview or via a self-completion questionnaire. The latter method of data collection generally yields higher levels of loneliness. Scale scores were dichotomized, with affirmative answers to two or more items taken as indicating loneliness. Given the differences in survey sample composition (e.g. age range, stratification criteria), Van Tilburg controlled for age, marital status, and gender. Note that Van Tilburg's study does not assess changes in loneliness that might be linked with changes in population composition. Rather, his analyses provide insight into a possible secular trend in loneliness.

Van Tilburg's findings are summarized in Fig. 3, which shows the proportion of lonely people over time. Contrary to popular belief, loneliness levels have been decreasing over time rather than increasing. In additional analyses, Van Tilburg examined trends in loneliness within homogeneous marital status and age samples. The decrease in loneliness is predominantly evident in subsamples of the married, which happen to involve the largest numbers of respondents. The results are less robust for non-married respondents. For example, whereas the category of nevermarried 65-75-year olds shows an increase in loneliness over time, older divorced and widowed groups show decreases in loneliness over the 20-year period.

Repeated cross-sectional studies using a single-item measure of loneliness consistently show either a decrease or no change in loneliness over time. In Germany, the prevalence of loneliness in the general population dropped from $19 \%$ in 1949 to $12 \%$ in 1963, and hovered between 4 and 8\% between 1973 and 1995 (Döring 1997). Survey data collected in England in 1948, 1957, 1963 and 2001 show that the proportion of older adults reporting they were "often lonely" ranged from 5 to $9 \%$ and showed no increase (Victor et al. 2002). Flemish data show a decrease

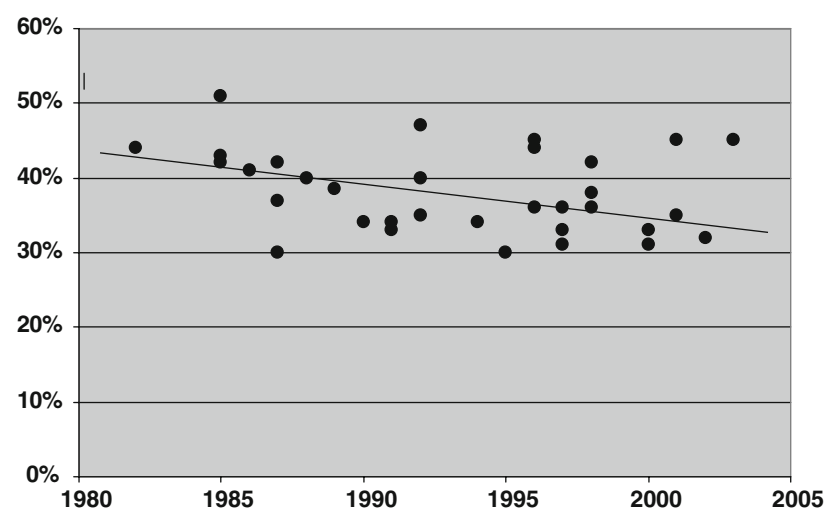

Fig. 3 Repeated cross-sectional assessments of loneliness in the Netherlands (\% lonely). Based on findings reported in Van Tilburg (2005) from $10 \%$ in 1985 to $8 \%$ in 2001 in the proportion of those aged 65 and above stating they were "often lonely" (Vanderleyden and Heylen 2007).

In a 2008 study, Van Tilburg used the Longitudinal Aging Study Amsterdam (LASA) to gain insight into changes in loneliness in the older adult population between 1992 and 2006. The LASA-sample is stratified by age and gender, so Van Tilburg used data on loneliness differentials by age, marital status and gender to produce estimates of loneliness for the general older adult population of the Netherlands. Both indirect (i.e. the De Jong Gierveld loneliness scale) and direct (i.e. the loneliness item from the CES-D) measures were included. Results show different trends, depending on the loneliness measure and cut-off point. Scores for the indirect measure showed no changes in loneliness between 1992 and 2006. Scores for the direct measure showed an increase from $16 \%$ in 1992 to $21 \%$ in 2006 for what Van Tilburg referred to as "occasional or persistent loneliness", that is older adults reporting they were lonely sometimes, often, mostly or always during the past week. There was no increase for "persistent loneliness" (feeling lonely often, mostly or always during the past week): the estimates were 5\% for 1992 and 4\% for 2006. To find out whether older adults are less reluctant to report loneliness given a greater acceptance and recognition of psychological problems in society (cf. Döring 1997), Van Tilburg estimated the likelihood of reporting feeling lonely controlled for scores on the indirect measure. Again, an increase in loneliness over time was observed only for the lower cut-off (an increase between 1992 and 2006 of $6 \%$ for those with average scores on the loneliness scale) but not for the higher cut-off of "persistent loneliness" which showed a decrease with one percentage point.

Research on changes in loneliness during the past decades is hampered by methodological problems, such as the questionable comparability of samples across time, the employment of different measures of loneliness, and the limited generalizability of findings to the general population. Nevertheless, a consistent pattern emerges with regard to the proportion of people who often (or persistently) feel lonely. Contrary to popular belief, this proportion has not increased over time. Studies show either a decrease or no change over time.

\section{Conclusion}

Questions of quality of life in late life have been dominated by health issues (Walker and Mollenkopf 2007). Concerns about the costs of an ageing population, and concerns about how older adults can continue to be self-reliant so as not to be dependent on services have immediate policy relevance. Elusive issues such as loneliness and other indicators of 
social embeddedness have received less attention. The lack of attention is unfortunate, given that the quality of personal relationships is one of the best predictors of health and life expectancy (Dykstra 2007). These considerations formed the reason for focusing on older adult loneliness.

As Diener and Suh (1997) have noted, scientific findings on well-being sometimes contradict lay beliefs that are prevalent in our culture. Empirical research can help to distinguish myths from realities. I reviewed the research literature to determine whether findings from empirical studies contradict or support three commonly held assumptions about older adult loneliness.

The first, namely that loneliness is a problem specifically for older people finds only partial support. Loneliness is common only among the very old, that is, those aged 80 and over. Loneliness levels show little variation across midlife and early old age, whereas young adulthood is characterized by a relatively high prevalence of loneliness. Perlman (1988) has two explanations for why older adults are not as lonely a group as stereotypes suggest. The first is that the desired levels of contact might drop as rapidly as the actual level of contact. The second is that older adults might have higher ratings of the quality of their relationships. Older adults might be less lonely because they feel their social circumstances compare favorably in terms of earlier expectations or relative to peers.

Why do ageist stereotypes persist? As Tornstam (2007) notes, the adherence to the stereotype of lonely elderly is all the more striking given that the general public has become more knowledgeable about the circumstances of older adults. He reports on Sweden where the government has engaged in extensive efforts to combat negative stereotyping of aging and old age over the past decades. Compared to the early 1980s the Swedish public in 2005 more accurately assessed the financial, material, and residential conditions of the older adult population. Nevertheless, they continued to subscribe to negative images of the elderly as suffering from boredom, dissatisfaction and loneliness.

Abramson and Silverstein (2006) report that respondents who expressed a high level of anxiety about the aging process were most likely to overestimate the prevalence of loneliness experienced by older people. The authors point to a need to remind the general public that older people can still adapt well, enjoy life, and prosper in spite of the effects of aging. Hagestad and Uhlenberg (2006) argue that age segregation fosters ageist attitudes. Our societies are characterized by spatial, cultural and institutional arrangements that segregate old and young persons from each other, and restrict opportunities for individuals to form stable cross-age relationships. Although ageist stereotypes can be reduced through education that intentionally aims at suppressing them, Hagestad and Uhlenberg suggest that building sustained familiarity with individuals in other age groups is the safest route for breaking down prejudice and preventing discriminatory behaviors. Residential, recreational and work settings which facilitate "mutual socialization" (p. 647) between young and old are essential to promoting knowledge of other age groups and reducing stereotypical judgments.

The second commonly held assumption is that people in individualistic societies are lonelier. Findings on crossnational differences in loneliness in Europe showed progressively increasing levels from north to south. This pattern is contrary to stereotypes which tend to equate the individualism and de-familialism (Esping-Andersen 1999) of the Scandinavian and the Continental European countries with high levels of social isolation. Though loneliness data for former communist countries are scarce, findings suggest that those countries rank highest in terms of the prevalence of loneliness. A similar pattern emerges with regard to general life satisfaction. Delhey (2004) reports that the Danes feel most satisfied, closely followed by the Dutch, the Luxembourgers and the Swedes, while Portugal and Greece are the least satisfied countries among the EU-15 member states. The most bottom ranks are occupied by the new member states with the exceptions of Slovenia, Cyprus, Malta, and the Czech Republic. Delhey (p. 65) speaks of a "new, dominant west-east gap in subjective well-being ... [which] will take the place of the less marked North-South gap, which has been dominant up to now".

The number of studies on cross-national differences in older adult loneliness is limited. Few are based on data collections designed for comparative purposes. The most common procedure is to make existing data sets as comparable as possible, acknowledging the limitations. The arrival of harmonized datasets, such as the Survey of Health and Retirement in Europe (SHARE) and the Generations and Gender Survey (GGS), will undoubtedly lead to increased interest in cross-national comparisons of loneliness and other indicators of quality of life. In terms of explanatory frameworks, the typical approach is to examine whether well-known determinants of loneliness such as partner status, health and quality of social interactions operate in a similar way across countries. Theoretical arguments as to why determinants might differ or might be similar are not always given (cf. Tesch-Römer and Von Kondratowitz 2006). A critical perspective on the portability of different explanatory models is required (Walker 2005).

Many questions remain. One of the challenges for crossnational comparative research on loneliness is to unravel "objective" circumstances, frames of reference, and response sets. Are older members of familialistic cultures lonelier because they are unaccustomed to fending for themselves and their lesser self-reliance makes them more vulnerable to the relationship losses that accompany old 
age? Do individualistic people consciously strive to avoid loneliness because privacy and optimism are highly valued in individualistic societies? Do people in former communist countries report higher levels of loneliness because a "litany of suffering", (Ries 1997 as cited in Pietilä and Rytkönen 2008) is a way of articulating the insecurities that the transformation to a capitalist system has brought them? These questions underscore the importance of considering people's normative orientations in the cultural context of the country in which they live. They also require supplementing large-scale data collections with in-depth qualitative analyses and an insider's analysis of discursive practices in the various countries.

The third commonly held assumption is that loneliness has increased over time. Findings showed the opposite trend: levels of loneliness have been decreasing over time, albeit slightly, or they have remained unchanged, depending on the studies that are considered. Loneliness is not the only outcome showing a change for the better. In so far they are available, trend data reveal that since the 1950s average happiness has increased slightly in rich nations and considerably in developing nations (Veenhoven and Hagerty 2006). The few empirical studies that have been carried out on changes in family relationships across time fail to report a decline in contact and quality-contrary to popular opinion. Two cross-sectional surveys conducted in 1979 and 1994 among older adults in two contrasting regions of Switzerland show that the frequency of family visits increased in both regions, and that a greater proportion received help from family members in the more recent survey (Vollenwyder et al. 2002). A Dutch cohort study comparing 55-65-year olds in 1992 with 55-65-year olds in 2002 (Van der Pas et al. 2007) shows that parents in the late cohort had higher levels of contact and support exchange with their children than parents in the early cohort.

Greater reflexivity, which means an increased tendency for individuals to reflect actively and critically on their experiences and relationships, might be the driving force behind the decline in loneliness and the improvement in personal relationships. One of the transformations of late modernity is that people are architects of their lives (Giddens 1991). Allan (2008) argues that individuals are more open to the possibility that relationships can be changed through individual agency rather than tacitly accepting them as a given of social life. There is also an increased flexibility to cast relationships in ways that best suit the lifestyles people are pursuing. More generally, and thanks to the contributions of popular psychology publications, women's magazines, and talk shows, there is an increased awareness among the general public of the importance in life of personal relationships. Presumably, people-both young and old - are nowadays better motivated and better skilled at maintaining satisfying relationships.
Acknowledgments Earlier versions of this manuscript were presented at the 2006 World Ageing \& Generations Congress 2006 in St. Gallen, Switzerland, and at the 2007 European Congress of the International Association of Gerontology and Geriatrics in Saint Petersburg, Russia, both times in sessions on "Quality of Life in Old Age" organized by Alan Walker.

Open Access This article is distributed under the terms of the Creative Commons Attribution Noncommercial License which permits any noncommercial use, distribution, and reproduction in any medium, provided the original author(s) and source are credited.

\section{References}

Abramson A, Silverstein M (2006) Images of aging in America 2004. AARP and the University of Southern California, Washington

Allan GA (2008) Flexibility, friendship and family. Pers Relatsh $15: 1-16$

Andrews FM, Withey SB (1976) Social indicators of well-being: American's perceptions of life quality. Plenum, New York

De Jong Gierveld J (1987) Developing and testing a model of loneliness. J Pers Soc Psychol 53:119-128

De Jong Gierveld J (1998) A review of loneliness: concept and definitions, determinants and consequences. Rev Clin Gerontol 8:73-80

De Jong Gierveld J (2008) Intergenerational relationships and transfers between older adults and their co-resident and not coresident children. Paper presented at the 2008 European Population Conference, Barcelona, 9-12 July

De Jong Gierveld J, Kamphuis F (1985) The development of a Raschtype loneliness scale. Appl Psychol Meas 9:289-299

De Jong Gierveld J, Van Tilburg T (1999) Living arrangements of older adults in the Netherlands and Italy: coresidence values and behaviour and their consequences for loneliness. J Cross Cult Gerontol 14:1-24

De Jong Gierveld J, Van Tilburg T (2006) A 6-item scale for overall, emotional, and social loneliness; confirmatory tests on survey data. Res Aging 28:582-598

De Jong Gierveld J, Van Tilburg TG, Dykstra PA (2006) Loneliness and social isolation. In: Vangelisti A, Perlman D (eds) The Cambridge handbook of personal relationships. Cambridge University Press, New York, pp 485-499

Delhey J (2004) Life satisfaction in an enlarged Europe. Office for Official Publications of the European Communities, Luxembourg

Diener E, Suh E (1997) Measuring quality of life: economic, social, and subjective indicators. Soc Indic Res 40:189-216

Döring N (1997) Einsamkeit in die "Informationsgesellschaft". ZUMA-Nachrichten 40(21):36-52

Drennan J, Treacy M, Butler M, Byrne A, Feally G, Frazer K, Irving $\mathrm{K}$ (2008) The experience of social and emotional loneliness among older people in Ireland. Ageing Soc 28:1113-1132

Dykstra PA (1995) Loneliness among the never and formerly married: the importance of supportive friendships and a desire for independence. J Gerontol 50B:S321-S329

Dykstra P (2007) Aging and social support. In: Ritzer G (ed) The Blackwell encyclopedia of sociology. Blackwell, Oxford, pp 8893

Dykstra PA, Fokkema T (2007) Social and emotional loneliness among divorced and married men and women: comparing the deficit and cognitive perspectives. Basic Appl Soc Psychol 29:1-12

Dykstra PA, Van Tilburg TG, De Jong Gierveld J (2005) Changes in older adult loneliness: results from a seven-year longitudinal study. Res Aging 27:725-747 
Esping-Andersen G (1999) Social foundations of postindustrial economies. Oxford University Press, Oxford

Giddens A (1991) Modernity and self-identity: self and society in the late modern age. Polity Press, Cambridge

Hagestad GO, Uhlenberg P (2006) Should we be concerned about age segregation? Res Aging 28:638-653

Halvorsrud L, Kalfoss M (2007) The conceptualization and measurement of quality of life in older adults: a review of empirical studies published during 1994-2006. Eur J Ageing 4:229-246

Hank K (2007) Proximity and contacts between older parents and their children: a European Comparison. J Marriage Fam 69:157-173

Heikkinen RL, Berg S, Avlund K (1995) Depressive symptoms in late life. J Cross Cult Gerontol 10:315-330

Hughes ME, Waite LJ, Hawkley LC, Cacioppo JT (2004) A short scale for measuring loneliness in large surveys: results from two population-based studies. Res Aging 26:655-672

Johnson DP, Mullins LC (1987) Growing old and lonely in different societies: toward a comparative perspective. J Cross Cult Gerontol 2:257-275

Jylhä M (2004) Old age and loneliness: cross-sectional and longitudinal analyses in the Tampere longitudinal study on aging. Can J Aging 23:157-168

Jylhä M, Jokela J (1990) Individual experiences as cultural: a crosscultural study on loneliness among the elderly. Ageing Soc $10: 295-315$

Kalmijn M, Saraceno C (2008) A comparative perspective on intergenerational support: responsiveness to parental needs in individualistic and familialistic countries. Eur Soc 10:479-508

Motel-Klingebiel A, Von Kondratowitz H-J, Tesch-Römer C (2004) Social inequality in later life: cross-national comparison of quality of life. Eur J Ageing 1:6-14

National Council on the Aging (2000) American perceptions of aging in the 21st century: chart book in the myths and realities of aging series. National Council on the Aging, Washington, DC

Peplau LA, Perlman D (1982) Perspectives on loneliness. In: Peplau LA, Perlman D (eds) Loneliness: a sourcebook of current theory, research and practice. Wiley, New York, pp 1-18

Perlman D (1988) Loneliness: a life-span, family perspective. In: Milardo RM (ed) Families and social networks. Sage, London, pp 190-220

Perlman D (2004) European and Canadian studies of loneliness among seniors. Can J Aging 23:181-188

Perlman D, Peplau LA (1981) Toward a social psychology of loneliness. In: Gilmour R, Duck S (eds) Personal relationships 3: personal relationships in disorder. Academic Press, London, pp $31-56$

Perlman D, Peplau LA (1984) Loneliness research: a survey of empirical findings. In: Peplau LA, Goldston SE (eds) Preventing the harmful consequences of severe and persistent loneliness. DHHS publication no. ADM 84-112. US Government Printing Office, Washington, DC, pp 13-46

Pietilä I, Rytkönen M (2008) Coping with stress and by stress: Russian men and women talking about transition, stress and health. Soc Sci Med 66:327-338

Pinquart M, Sörensen S (2001) Influence on loneliness in older adults: a meta-analysis. Basic Appl Soc Psychol 23:245-266

Platz M (2005) Et ældreliv i ensomheid? Gerontologisk Institut, Hellerup, DK (with summary in English)

Radloff LS (1977) The CES-D scale: a self-report depression scale for research in the general population. Appl Psychol Meas 1:385401

Reher DS (1998) Family ties in western Europe. Popul Dev Rev 24:203-234

Revenson TA (1986) Debunking the myth of loneliness in late life. In: Seidman E, Rappaport J (eds) Redefining social problems. Plenum Press, New York, pp 115-135
Samuelsson G, Andersson L, Hagberg B (1998) Loneliness in relation to social, psychological and medical variables over a 13 -year period: a study of the elderly in a Swedish rural district. J Ment Health Aging 4:361-378

Scharf T, De Jong Gierveld J (2008) Loneliness in urban neighbourhoods: an Anglo-Dutch comparison. Eur J Ageing 5:103-115

Skevington SM, Lotfy M, O'Connell KA (2004) The World Health Organization's WHOQOL-BREF quality of life assessment: psychometric properties and results of the international field trial. A report from the WHOQOL Group. Qual Life Res 13:299-310

Tesch-Römer C, Von Kondratowitz H-J (2006) Comparative ageing research: a flourishing field in need of theoretical cultivation. Eur J Ageing 3:155-167

Tijhuis MAR, De Jong Gierveld J, Feskens EJM, Kromhout D (1999) Changes in and factors related to loneliness in older men: the Zutphen elderly study. Age Ageing 28:491-495

Tomassini C, Glaser K, Wolf DA, Broese van Groenou MI, Grundy E (2004) Living arrangements among older people: an overview of trends in Europe and the USA. Popul Trends 115:24-34

Tornstam L (2007) Stereotypes of old people persist: a Swedish "Facts on aging quiz" in a 23 -year comparative perspective. Int J Aging Later Life 2:33-59

United Nations (2005) Generations and gender programme: survey instruments. United Nations Economic Commission for Europe and United Nations Population Fund, New York and Geneva

Van Baarsen B, Snijders T, Smit JH, Van Duijn MAJ (2001) Lonely but not alone: emotional isolation and social isolation as two distinct dimensions of loneliness in older people. Educ Psychol Meas 61:119-135

Van der Pas S, Van Tilburg T, Knipscheer K (2007) Changes in contact and support within intergenerational relationships in the Netherlands: a cohort and time-sequential perspective. In: Owens T, Suitor JJ (eds) Advances in life course research: interpersonal relations across the life course, vol 12. Elsevier, London, pp 243-274

Van Tilburg T (2005) Loneliness from 1978 to 2003: a historical time analysis among Dutch adults. Paper prepared on the occasion of the farewell of Jenny Gierveld. Vrije Universiteit, Amsterdam

Van Tilburg T (2008) Today's older persons: Increasingly lonely or increasingly likely to report loneliness? Paper presented at the 61 st annual scientific meeting of the Gerontological Society of America, National Harbor, USA, 21-25 November

Van Tilburg TG, De Jong Gierveld J, Lecchini L, Marsiglia D (1998) Social integration and loneliness: a comparative study among older adults in the Netherlands and Tuscany, Italy. J Soc Pers Relat 15:740-754

Van Tilburg TG, Havens B, De Jong Gierveld J (2004) Loneliness among older adults in the Netherlands, Italy and Canada: a multifaceted comparison. Can J Aging 23:169-180

Vanderleyden L, Heylen L (2007) Ouderen, hun sociale contacten en de beleving ervan: continuiteit of verandering? T Sociol 28:5278

Veenhoven R, Hagerty M (2006) Rising happiness in nations 19462004: a reply to Easterlin. Soc Indic Res 79:421-436

Victor CR, Scrambler SJ, Shah SG, Cook D, Harris T, Rink E, De Wilde S (2002) Has loneliness amongst older people increased? An investigation into variations between cohorts. Ageing Soc 22:585-597

Vollenwyder N, Bickel J-F, Lalive d'Epinay C, Maystre C (2002) The elderly and their families, 1979-94: changing networks and relationships. Curr Sociol 50:263-280

Walker A (1993) Age and attitudes: main results from a Eurobarometer survey. Commission of the European Communities, Bruxelles 
Walker A (2005) A European perspective on quality of life in old age. Eur J Ageing 2:2-12

Walker A, Mollenkopf H (2007) International and multidisciplinary perspectives on quality of life in old age: conceptual issues. In: Mollenkopf H, Walker A (eds) Quality of life in old age: international and multi-disciplinary issues. Springer, New York, pp 3-13
Weiss RS (1973) Loneliness: the experience of emotional and social isolation. MIT Press, Cambridge

Wenger GC, Davies R, Shahtahmasebi S, Scott A (1996) Social isolation and loneliness in old age: review and model refinement. Ageing Soc 16:333-358 